\title{
Creating shareable representations of practice
}

\author{
Peter Goodyear and Christine Steeples \\ Centre for Studies in Advanced Learning Technology (CSALT), Lancaster University \\ Email:P.Goodyear@lancaster.ac.uk.
}

This paper reports work on the use of asynchronous multimedia conferencing (AMC) to support collaborative continuing professional development. In particular it explores how we may use multimedia communications technologies to enable key elements of real-world working knowledge, that are tacit and embedded in working practices, to be rendered into shareable forms for professional learning. We believe multimedia communications technology can offer innovative ways of capturing rich examples of working practices and tacit knowledge, and for sharing and subjecting these artefacts to scrutiny, debate and refinement within a community of learners. More explicitly, we see participants in a geographically distributed community of practice being able to create, annotate, discuss and reflect upon videoclips of their working practices within the multimedia conferencing environment. This paper summarizes some studies that cast light on how representations of practice may be captured for use in an AMC environment.

\section{Introduction}

This paper arises from a programme of research and postgraduate teaching which, over the last ten years, has sought to explore ways of providing better support for the continuing professional development of geographically dispersed communities of skilled workers through the use of computer-mediated communications (Goodyear, 1995). One issue is the problem of creating sustained on-line interactions that draw on both practitioner experience and research-based knowledge. Part of our explanation for the difficulties in stimulating a sustained and inclusive discussion, which bridges between academia and practice, lies in the affordances of text-based communication. Aspects of practice, we suggest, are difficult to render through written language. It can also be very hard to articulate practical knowledge that is held and used in tacit form. The situation is exacerbated by some of the expectations which participants bring to the electronic discussion. For example, one can begin to create a comprehensible description of a current 
work issue through writing an extended account of the .necessary organizational background - tàsks, personnel, 'house-style', etc. - but such extended contributions are neither expected nor welcome in most on-line communications environments. In the rest of this paper, we look at some- of the ways in which multimedia communications (using video, voice, etc.) may be able to help with this block.

\section{Technology for professional development within a distributed community of practice}

Table 1 is an attempt to summarize some of the strengths and weaknesses of synchronous, asynchronous, text-based and multimedia communications. The table brings home the point that there is a very uneven understanding of the four areas. Much more is known about synchronous text-based communication. (e.g. McConnell, 1994) than about synchronous multimedia communication, and very little indeed is known about either asynchronous text-based or asynchronous multimedia communication (though see Murphy and Collins, 1997; Collis and Smith, 1997). It is important to recognize that the 'strengths and weaknesses' in the table have to be interpreted as things which can be claimed 'in principle'. They will not always prove to be characteristics of these types of communication, since other factors intervene between media type and outcome.

Bearing in mind such caveats, our focus on asynchronous multimedia communication brings the following potential strengths and weaknesses into the foreground. AMC could be said to combine richness of communication and the possibility of quickly creating vivid accounts and demonstrations of practice with flexibility in the use of time (participants do not have to be available at the same instant; there is opportunity for reflection on what is seen and heard). But AMC is also likely to create materials that are relatively hard to index and search, and are relatively demanding in terms of computer memory; bandwidth and storage space, relative that is to text-based materials. Finally, the price of temporal flexibility is that asynchronous communication cannot benefit from the rapid turn-taking and negotiation which is characteristic of, and highly valued in, synchronous communication (Boden and Molotch, 1994).

\section{Methodology: researching the requirements for learning technologies}

We have adopted a research framework that is becoming known as 'the ergonomics of learning environments' (see e.g. Goodyear, 1997; in press): The essence of the approach is that we:

- Distinguish between learning tasks and learning activities.(tasks are what teachers set; activities are what learners actually do).

- Use the best pedagogical resources at our. disposal to design good tasks.

- But design technology around a thorough understanding of activity.

What we are doing is no more than applying lessons learned from mainstream ergonomics, $\mathrm{HCI}$ and software engineering to the world of educational technology. That:is, one should build technology around real user needs rather than around an idealized 'manager's'. view of what is needed. The approach is appropriate wherever one cannot assume that learners 


\begin{tabular}{|c|c|c|c|c|}
\hline & Synchronous & Asynchronous & Strengths & Weaknesses \\
\hline Text-based & $\begin{array}{l}\text { e.g. IRC } \\
\text { (Internet } \\
\text { Relay Chat) }\end{array}$ & e.g. email, CMC & $\begin{array}{l}\text { encourages } \\
\text { clarity of } \\
\text { expression, } \\
\text { formalization } \\
\text { of knowledge } \\
\text { etc.; indexable, } \\
\text { searchable; } \\
\text { small data files }\end{array}$ & $\begin{array}{l}\text { time-consuming } \\
\text { to produce; hard } \\
\text { to capture } \\
\text { practices'; hard } \\
\text { to eradicate or } \\
\text { control } \\
\text { ambiguity? }\end{array}$ \\
\hline Multi-media & $\begin{array}{l}\text { e.g. live } \\
\text { video- } \\
\text { conference }\end{array}$ & $\begin{array}{l}\text { e.g. video-on- } \\
\text { demand; video- } \\
\text { mail }\end{array}$ & $\begin{array}{l}\text { vivid, rich, } \\
\text { allows } \\
\text { showing as } \\
\text { well as } \\
\text { telling, can be } \\
\text { easy and quick } \\
\text { to produce and } \\
\text { read }\end{array}$ & 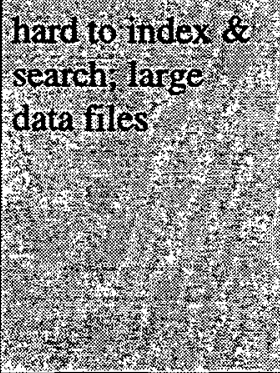 \\
\hline Strengths & $\begin{array}{l}\text { supports } \\
\text { interactive } \\
\text { communic- } \\
\text { ation; timely; } \\
\text { sense of event } \\
\text { \& audience }\end{array}$ & $\begin{array}{l}\text { time to reflect } \\
\text { flexible use of } \\
\text { time }\end{array}$ & & \\
\hline Weaknesses & $\begin{array}{l}\text { inflexible use } \\
\text { of time; may } \\
\text { not scale up } \\
\text { to large } \\
\text { numbers }\end{array}$ & $\begin{array}{l}\text { can be slow or } \\
\text { cumbersome }\end{array}$ & & \\
\hline
\end{tabular}

Table I:In principle' strengths and weaknesses of synchronous and asynchronous multimedia and text-based communications.

are highly compliant (i.e. it should suit most areas of Higher Education better than it suits military training, for example).

The focus, with this approach, shifts to illuminating what learners actually do, once they have entered into a programme of learning activity of some kind. In our case, the programme of activity is one of continuing professional development in which the "high level pedagogy' prioritizes the sharing of vocational experience, the collective analysis, discussion, critique and improvement of situated working practices, the articulation and examination of tacit knowledge, etc. We need to understand how the members of a distributed community of practice engage in such activity, and how their existing 
technology shapes and limits what they do, so that we can understand how to improve the technology at their disposal. This has much in common with user-centred, participative or ethnographic approaches to software/information systems engineering (see e.g. Norman and Draper, 1986; Schuler and Namioka, 1993; Shapiro, 1994).

In this paper, we report on one small but important area of interaction between technology and learner activity. We concentrate on some of the activities associated with creating a multimedia representation of practice, using two approaches, which we have dubbed 'fly on the wall' and 'action with commentary'. We use some example multimedia objects as our data (cf. Boden, 1994, 216ff; Simco and Warin, 1997) and build a conceptual model of those objects as a way of simplifying and ordering the space of possibilities within which AMCbased continuing professional development might occur. It is important to emphasize that this conceptual model is grounded in the data and in our experience of interrogating that data. It is not an a-priori model of the kind that arises from so-called rational analysis.

\section{The making of shareable representations of practice as 'raw' videoclips and videoclips of action with commentary}

Our method of working has been adopted as a way of understanding some of the requirements for a properly functioning AMC environment which is to be used in a CPD setting of the kind we characterized earlier. Understanding requirements for a future technology involves creating a map of likely uses and analysing these uses in some detail. Mapping the space of likely uses can be helped by observing and reflecting on the origination of videoclips of different kinds, trying to identify the attributes which make one 'kind' of clip different (in important ways) from another, and trying to relate kinds of clip to processes of origination.

We concentrate here on two kinds of clip. But we also locate these within a broader taxonomy of clips. The kinds of clip with which we are concerned here are:

- clips which are, in some sense, 'raw' representations of practice: clips generated by techniques which TV documentary makers call 'fly on the wall', because the camera and the fact that a representation is being created - are meant to have no significant disruptive effect on the practice;

- clips which we call 'action with commentary': clips in which the practitioner adds a voice track to a video representation of an unfolding practice, as a way of making that practice more comprehensible to others.

\section{The data}

The clips we have been using can be viewed at our project website (the URL is given at the end of the paper). Each of the clips can be considered as data from the research. The reader may find it useful to look at the clips while reading this article. Additional data come from our observations of the clips being made and from statements by those making the clips (before and after the event). With each clip, members of the research team discussed a number of aspects of the origination of the clip, tried to define some of its key attributes and tried to use this discussion in an iterative construction of a 'space' of kinds of clips. The process is not unlike the construction of analytic categories through 
successive passes through a data set: building theoretical constructs that are grounded in qualitative data (cf. Glaser and Strauss, 1967).

Analysis 1:Types of video representations of practice

In the first part of the analysis, we offer a sketch of six emergent 'kinds' of video representation of practice. These can be arranged along a continuum of increasing abstraction from actuality. In the following descriptions we use the term 'subject' to denote practitioner.

\section{Fly on the wall}

In this type of representation, a camera is set up to capture practice in situ. The practice unfolds with as little attention to the video capture as possible. Depending upon the nature of the practice, the representation captured may or may not include speech from the subject(s) and also may or may not include visible physical activity. The practice may be primarily cognitive (i.e. going on inside the subject's head) and therefore may involve little visible action.

\section{Think aloud}

This is also described as 'talking while doing' or concurrent verbalization. Here the subjects are filmed as they engage in the practice to be represented. The subjects will have been prompted to think aloud as they work. The practice depicted in this type of clip is most likely to be one that is normally performed alone or at least to be one that does not normally involve speech (otherwise there is scope for interference and confusion between speech-in-the-task and speech-about-the-task).

The difference between this type of representation and the following type (action with commentary) depends on a claim about the validity of using concurrent verbalization to gain access to the subject's cognitive processes. Drawing on the views of Ericsson and Simon (1993) on this matter, we call a clip 'think aloud' if there are reasonable grounds to believe that what we are getting in the audio track is a reasonable reflection of the subject's task-related cognitive processes, and is not significantly biased by the subject's desire to provide a tidied-up account of what they are doing.

\section{Action with commentary}

In this type of representation, the subjects are encouraged to explain what they are doing as they work. This is different from thinking aloud because it requires the subject to create a commentary. They are creating their representation with an audience in mind, rather than being restricted to a concurrent verbalization on the task itself. The commentary may be a continuous explanation as the practice unfolds, or it may be that the subjects begin, end or interrupt the action with a commentary.

\section{Talking head}

This kind of representation moves further away again from the 'purity' of practice. Here the subjects speak to camera about a practice in which they engage and explain aspects of it. It is therefore likely to be a more discursive and reflective account than the accounts in the earlier examples. It may be done 'on the fly' rather than rehearsed or it may be prepared in advance, though not scripted (see below). 
The subject will also be conscious of audience and will be explaining a practice rather than participating in it. The clip may offer a mixture of description and reflective comment. Of course as the subjects talk about the practice they might wish to use artefacts to help clarify what they are saying. Such use of artefacts (etc.) from the work environment may be a useful source of 'grounding' in talking head clips: making it harder for the subject to depart (intentionally or unintentionally) from the actuality of their practices.

\section{Prepared script}

In this type of representation, the subject prepares a written description (and possibly commentary) of a practice in advance of performance. This script may be used as a prompt, or followed closely for verbatim reporting. This is most likely to be a single subject activity.

\section{Professionally acted}

In this final type, a professional actor who adopts the role of the actual practitioner plays the subject engaged in a practice. This type of representation might involve scripting by the actual subject or could be prepared by a professional writer or production team in consultation with the practitioner. An example would be a training video produced commercially and used to illustrate how a skill or task should be undertaken. However, we think this latter type of representation is less relevant to our goals since our purpose is to help practitioners, for themselves, tease out tacit knowledge embedded within their own working practices.

Analysis 2: 'Fly on the wall' and 'action with commentary'

We now offer a few notes about what are emerging as two potentially significant kinds of representations of practice. As we shall see, one appears to have more potential than the other.

\section{Fly on the wall}

Fly-on-the-wall representations are intuitively appealing because, in principle, they are most true to practice. To the extent that the presence of a camera (or cameras) is ignored, they offer an unbiased picture of how work is actually done. It is therefore unfortunate that fly on the wall proves to have a number of major limitations. (These limitations are rendered less visible in fly-on-the-wall programmes for TV. In this currently popular genre, many hours of videotape are skilfully edited down to provide a representation judged to be readily comprehensible by the viewer.) As a method of cost-effectively representing practice for use in AMC, fly on the wall proves to be a non-starter. There are some exceptions:

- for creating a representation of a temporally and spatially delimited 'event', such as a meeting (many working practices ramble through time and space and are interleaved with other working practices);

- for other kinds of activity involving either audible discussion or visible activity, where there is sufficient 'bounding' of the activity for its shape to be apprehended and sufficient contextual information for its content to be understood;

- where the person creating the representation can be expected to edit the video to produce something understandable. 
Except in these kinds of circumstances, fly on the wall does not appear to be an efficient way of creating shareable representations.

\section{Action with commentary}

One use for fly on the wall is as base material on which a commentary may be overlaid. That is, a subject may create a representation of their practice - or that of others - by (a) selecting some appropriate clips of fly-on-the-wall video and (b) explaining what is going on through an audio track. Such a version of action with commentary has the virtue of being solidly rooted in real world practice, though the task of selection and editing may be both time-consuming and a source of bias.

In general, action with commentary appears to have a useful balance of strengths over weaknesses. It has a firmer grounding in real world activity than is the case with 'talking head', for example. It can be created without excessive demands on the subject's time. In our trial sessions, good action with commentary clips was often made with no more than a minute or two's preparation. While the making of this kind of representation may not suit everyone, it seems to us to be sufficiently credible to warrant the investment of time by the project team in developing some further models of how it may be done and to refine our ideas about the requisite skills and technology.

\section{Further work}

The next main studies to be undertaken are intended to help with our understanding of the use of audio commentary on a video representation (as in action with commentary). In particular, we want to get closer to answers on the following matters:

- What processes are at work when a practitioner constructs an audio account to accompany a video representation of an aspect of their working practice?

- How do other practitioners interrogate the multimedia resources thereby created (and what do they 'take' from them)?

- What kinds of capture technology (camera set-ups, editing tools, etc.) are best suited to action with commentary approaches?

- What kinds of interface (to an AMC database) are best suited to the needs of those creating and browsing such representations?

\section{Acknowledgements}

This work has been carried out within the SHARP project, which is partially supported by the EC SOCRATES programme's Open and Distance Learning action line. Further details of SHARP can be found on the World Wide Web at http://www.lancs.ac.uk/users/edres/ research/sharp/index.htm.

We thank our colleagues in the SHARP team: Bodil Ask, Sonia Bartoluzzi, Harald Haugen, Nigel Oxley, Tasos Koutoumanos, Cleo Sgouropoulou-Koutoumanou and Manolis Skordalakis. 


\section{References}

Boden, D. (1994), The Business of Talk: Organizations in Action, Cambridge: Polity.

Boden, D. and Molotch, H. (1994), 'The compulsion of proximity' in Friedland, R. and Boden, D. (eds.), NowHere: Space, Time and Modernity, Berkeley: University of California Press, 257-86.

Collis, B. and Smith, C. (1997), 'Desktop multimedia environments to support collaborative distance learning', Instructional Science 25 (6), 463-6.

Ericsson, K. and Simon, H. (1993), Protocol Analysis: Verbal Reports as Data (revised edition), Cambridge Mass: MIT Press.

Glaser, B. and Strauss, A. (1967), The Discovery of Grounded Theory: Strategies for Qualitative Research, Chicago: Aldine.

Goodyear, P. (1995), 'Asynchronous peer interaction in distance education: the evolution of goals, practices and technology', Training Research Journal, 1, 71-102.

Goodyear, P. (1997), 'The ergonomics of learning environments: learner-managed learning and new technology' in Creación de materiales para la innovación educativa con nuevas tecnologías, Malaga: Instituto de Ciencias de la Educacion, Universidad de Malaga, 7-17.

Goodyear, P. (in press), 'New technology in higher education: understanding the innovation process' in Eurelings, A. (ed.), Bringing Information Technology to Education, Dordrecht: Kluwer Academic Press.

Hambusch, R. (ed.), The Computer-mediated Education of Information Technology Professionals and Advanced End-users, Amsterdam: Elsevier.

McConnell, D. (1994), Implementing Computer-supported Co-operative Learning, London: Kogan Page.

Murphy, K. and Collins, M. (1997), 'Development of communication conventions in instructional electronic chats', paper given at Annual meeting of the American Educational Research Association, Chicago. Available at http://star.ucc.nau.edu/ mauri/ papers/aera97a.html.

Norman, D. and Draper, S. (eds.) (1986), User-centered System Design,. Hillsdale, New Jersey: Lawrence Erlbaum.

Schuler, D. and Namioka, A. (eds.) (1993), Participatory Design: Principles and Practices, Hillsdale New Jersey: Lawrence Eribaum.

Shapiro, D. (1994), 'The limits of ethnography', Proceedings of CSCW'94, 417-28.

Simco, N. and Warin, J. (1997), 'Validity in image-based research: an elaborated illustration of the issues', British Educational Research Journal, 23 (5), 661-72. 